Research Article

\title{
Evaluation of Seismic Performance and Soil-Structure Interaction (SSI) for Piloti-Type Buildings considering Korean Geotechnical Conditions
}

\author{
Seung Dae Kim $\mathbb{D}^{D}$, Jaeyong Yoon $\mathbb{D}$, Wanjei Cho $\mathbb{D}$, and Jungwhee Lee \\ Department of Civil and Environmental Engineering, Dankook University, Yongin, Republic of Korea \\ Correspondence should be addressed to Jaeyong Yoon; hiroader@dankook.ac.kr
}

Received 24 May 2021; Revised 11 August 2021; Accepted 26 August 2021; Published 15 September 2021

Academic Editor: Huseyin Bilgin

Copyright ( 2021 Seung Dae Kim et al. This is an open access article distributed under the Creative Commons Attribution License, which permits unrestricted use, distribution, and reproduction in any medium, provided the original work is properly cited.

\begin{abstract}
Piloti-type structure is a popular architectural style consisting of only columns or minimum number of shear-resisting walls on the first floor. The large difference in lateral stiffness between the first and the upper floors makes the structure very vulnerable to earthquakes. Through the recent earthquakes in Gyeongju (2016) and Pohang (2017), due to such structural disadvantages, many damage cases have been reported, especially in low-rise piloti-type buildings with five stories or less. In this study, seismic soilstructure interaction (SSI) analysis is conducted on low-rise piloti-type buildings considering Korean geotechnical characteristics, and the effect is analytically evaluated. To achieve this goal, seismic SSI analysis applying the measured Gyeongju earthquake and design response spectrum (DRM) based on the architectural design codes are conducted by constructing three-dimensional structural analysis models with a five-story piloti-type building and four different soil properties: fill (FI), alluvial soil (AS), weathered soil (WS), and weathered rock (WR). From the analysis results, it is found that WS soil is largely affected by the seismic SSI, and the influence of the seismic SSI is different for each soil type regardless of the type of earthquake. Through the parameter study, simple and reasonable estimates are proposed to consider the SSI effect on the base shear in low-rise piloti-type buildings.
\end{abstract}

\section{Introduction}

Piloti type is a widely adopted architectural type for multiunit housing in Korea due to the advantage of efficient use of space on the first floor. However, the large difference in lateral stiffness between the floor of pilotis (columns and walls) and the upper levels makes the structure very disadvantageous against earthquakes, causing the transverse shear deformation as shown in Figure 1(a), thereby resulting in shear failures in columns and walls in Figures 1(b) and 1(c) during earthquakes. Through the Gyeongju and Pohang earthquakes of magnitude 5.8 and 5.4 that occurred in Korea in August 2016 and November 2017, such damage cases have intensively been reported in piloti-type structures with five stories or less, and similar situations have also been observed in different countries $[2,3]$. Accordingly, studies on the evaluation of seismic behavior and seismic performance of low-rise piloti have been conducted $[1,4,5]$ in various aspects, but the study on the dynamic interaction between the underlying soil and the structures during earthquakes, that is, SSI, still remains at a fundamental level [6-8].

In general, it has been considered that seismic SSI analysis is conducted as necessary only in case of special facilities such as nuclear power plants, skyscrapers, or large structures requiring complicated structural analysis [9-11]. However, from the fact that the damage cases of Gyeongju earthquake were concentrated on the low-rise piloti [4] and from the ASCE guideline [12] and the recent research results [13] that the influence of the inertial interaction is greater in a rigid structure with a short natural period $\left(T_{n}<1.0 \mathrm{sec}\right)$ on mat or raft foundations, it is necessary to examine the influence of seismic SSI that occurs in low-rise piloti-type buildings occupying the absolute proportion of the architectural type.

Thus, the objective of this study is to analytically evaluate the influence of the seismic SSI effect with incorporating the 


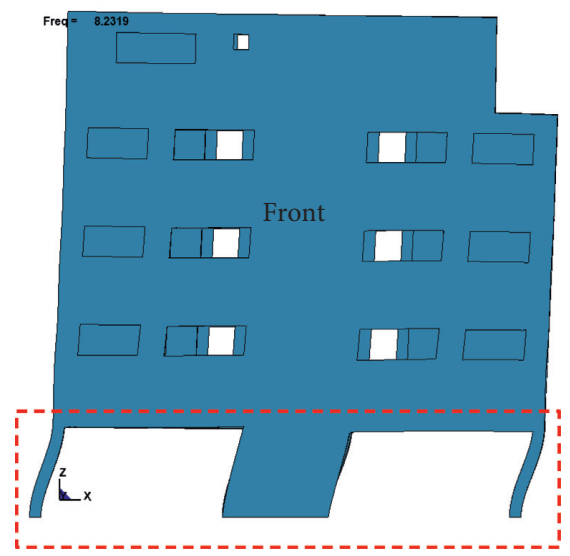

(a)

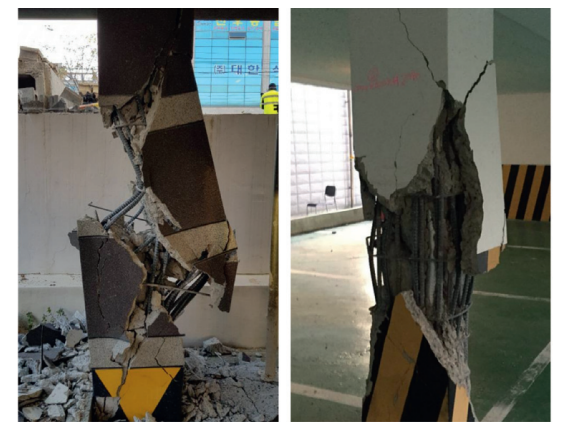

(c)

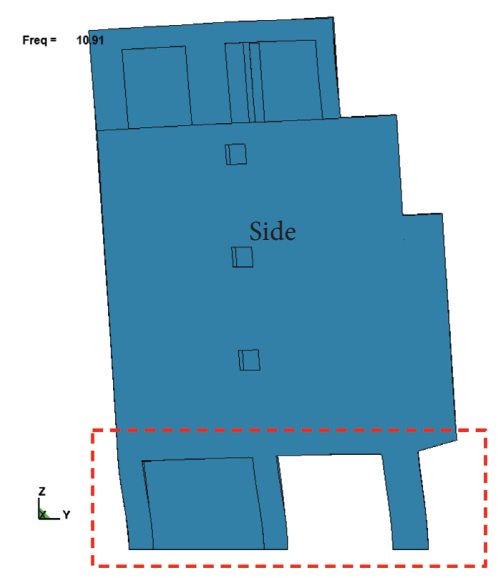

(b)

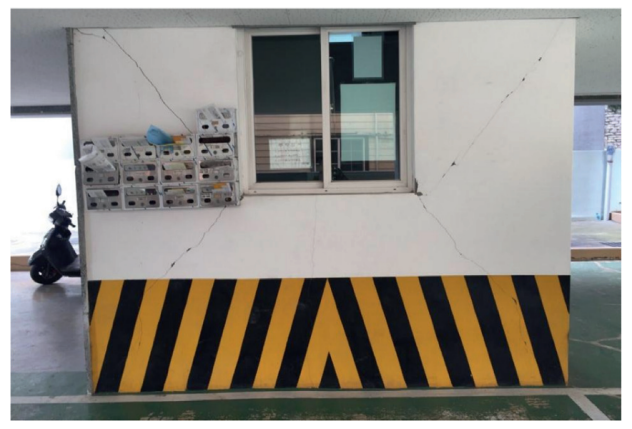

(d)

Figure 1: Examples of deformed shape and failure in columns and a wall on the $1^{\text {st }}$ floor of piloti-type buildings. (a) Front and side views of the deformed shapes of a five-story piloti-type building analysis model. (b) Shear failure examples in columns [1]. (c) A shear crack example on a wall [1].

domestic geotechnical properties for typical low-rise pilotitype buildings. To achieve this goal, this study performs two steps of analytical procedure as follows. First, after selecting a representative five-story piloti-type building and constructing a full finite element (FE) soil-structure model for each of the four soil models based on the geotechnical data, dynamic seismic SSI analysis is conducted by a seismic load from the Gyeongju earthquake of magnitude 5.8 that occurred in September 2016 applied to the model. In the second analysis, based on the results from the first analysis, a main structural parameter is defined and calculated in the building FE models, and a parametric study is conducted for each soil model to evaluate the SSI effect on the base shear. After the influence of the parameter is analyzed, simple and reasonable prediction values for the effect are presented, and these values are compared with the current architectural design guidelines.

\section{SSI Analysis Method and the Properties of the FE Model}

2.1. Seismic SSI Analysis Method with LS-DYNA. Since not only structural and soil dynamics but also various physical phenomena act in a complex manner in seismic SSI analysis, various analysis methods have been introduced to consider the differences among regional aspects, structural systems, and the complexity of the analysis [14]. There are two main methods of the SSI analysis. One is a relatively simple method, called "substructure" approach, which is very useful in terms of the consumption of analysis time. In this method, soil and structural domains are divided into two parts. Firstly, the response at the soil-structure interface due to seismic force generated in the ground is obtained, and then the response becomes the input to the foundation of the structure to obtain the response of the structure. In order to consider the SSI effect in this analysis, the boundary of the soil-structure is usually modeled as elastic springs and dampers. In recent studies, this method is applied to multistory buildings by modeling them with simple $2 \mathrm{D}$ or $3 \mathrm{D}$ frame elements $[9,10,13]$. The second method is a "direct" method that applies their individual properties to structural and soil domains, respectively, and directly analyzes the entire FE model. Though it consumes a lot of analysis time and resources as the behaviors of enough ground area and the structure must be analyzed as a whole, the method has widely been adopted owing to the development of computing performance in analysis programs these days. The difference between "substructure" and "direct" methods lies only in the approach to handling the mutual response around soil and structure interfaces. This is one of the most crucial issues in the seismic SSI analysis, and many studies have dealt with this problem [14]. With the development of 
various three-dimensional (3D) commercial analysis software, 3D seismic analysis using "direct" method has become possible, but there are still not many of them that provide reliable analysis basis for the SSI effects. A commercial program, ANSYS, was used to apply a frictional boundary element to the soil-structure interface [11], but the use of this element has not yet proven the reliability of the SSI effect on the interface. Therefore, in this study, an efficient and accurate seismic SSI analysis was performed by "direct" method using the SSI interface elements provided by LSDYNA (Version: smp d R8.0.0). The SSI analysis module in LS-DYNA is theoretically based on the domain reduction method (DRM) [15] and includes an internal command of "SSI_INTERFACE," which makes the implementation of seismic SSI analysis according to DRM theory possible by simply defining the surface of the boundary and allocating the interface elements between soil and structure foundation. Furthermore, it is very efficient that the responses of the soil and the foundation can be easily obtained by putting only the free-field ground motion as the effective seismic force into the assigned interface elements [16]. The validity of the analysis with LS-DYNA has been verified through several studies and literature up to date [17-19].

The range of a 3D FE model for an underlying soil should be divided into a finite boundary area (near-field) adjacent to the foundation of a structure and an unbounded and infinite area (far-field). Since the stress waves are inevitably reflected at the artificial interface that is introduced to separate the ground into two regions [18], the following aspects must be taken into account when modeling the underlying soil ground for effective seismic SSI analysis [17]. (1) The size of soil elements and the dimension of the domain should prevent the waves reflected from the structure due to the inertial interaction from propagating back into the ground, and (2) stress equilibrium must be established at the lateral boundary of the ground elements to effectively simulate infinite ground area. In this study, to adequately consider the effect of the infinite range of actual 3D ground, a sufficient scale of ground area and proper boundary conditions are set as described in a previous study [19].

\subsection{Geometric and Material Properties of the Objective} Structure for FE Models. In order to carry out the purpose of this study, a reinforced concrete piloti-type building, that is the most popular and typical type of the structure in Korea, is selected. The objective building is $13.3 \mathrm{~m}$ high with five stories, and the geometric features: direction, dimension of each floor, and location of columns and walls are shown in Figure 2.

As for the analysis model, a full 3D nonlinear solid model as shown in Figure 3(a) is constructed by considering properties of concrete and the reinforcement using the drawings of the columns and walls. The material properties include modulus of elasticity of concrete $\left(E_{c}=24,518 \mathrm{MPa}\right)$, design strength of concrete $\left(f_{c k}=20 \mathrm{MPa}\right)$, unit mass of concrete $\left(\rho_{c}=2,300 \mathrm{~kg} / \mathrm{m}^{3}\right)$, modulus of elasticity of rebars $\left(E_{s}=200,000 \mathrm{MPa}\right)$, yield strength of rebars $\left(f_{y}=400 \mathrm{MPa}\right)$, unit mass of rebars $\left(\rho_{\mathrm{s}}=7,850 \mathrm{~kg} / \mathrm{m}^{3}\right)$, and
Poisson's ratio of concrete and rebars $(\nu=0.3)$. Next, based on the full 3D FE model, an equivalent lumped mass frame model is made to increase the efficiency of analysis time and efforts. In constructing the stiffness of the equivalent model, force-displacement relationship of each floor between the full and the frame models is calculated to be equivalent, and the fundamental natural frequencies in east-west (EW) direction from the modal analysis are intended to match each other. Also, the modified modulus of elasticity of concrete, $E_{m}$ [20], is used to simulate reasonable sectional values and physical properties considering rebar effects in cross-sections. The lumped mass model constructed in this way is analyzed by applying each soil ground model as shown in Figure 3(b).

A linear elastic material model was applied to the frame element of the structure itself, and the underlying soil is analyzed using a 3D solid element with the Mohr-Coulomb material model. The geometric properties of the FE model for structural analysis are summarized in Table 1.

2.3. Geotechnical Properties of Soil Considered in the SSI Analysis. One of the most important factors in performing accurate seismic SSI analysis is to determine the geotechnical properties adequately [21]. However, in general seismic analysis and design process, it is extremely rare to take underlying soil properties into consideration since the foundation is usually assumed to be a fixed base. In general, as the soil properties for ground analysis and design have high variability for each country and region, it is also very difficult to find a unified standard for the properties even though the target site is limited to a certain region. In this situation, a number of researches have been conducted to suggest reasonable Korean domestic geotechnical characteristic values so that structural designers can easily apply to seismic design projects $[22,23]$. In particular, Sun et al. classified domestic soil into five categories: fill (FI), alluvial soil (AS), weathered soil (WS), weathered rock (WR), and bedrock (BR), and they presented standard values of the shear wave velocity for each soil, which are used as the most important variables in seismic SSI analysis [22]. Out of the five soil conditions suggested by Sun et al., the properties from only four grounds (FI, AS, WS, and WR) are adopted in the seismic SSI analysis for each soil condition in this study, except for the BR condition, which is a solid ground with a shear wave velocity greater than $1,524 \mathrm{~m} / \mathrm{s}$ $(5,000 \mathrm{ft} / \mathrm{s})$ and therefore the SSI effect is judged to be negligible [24]. Table 2 shows the values of the geotechnical properties for the Mohr-Coulomb material model for each soil type used in the analysis.

In this study, the default values of properties related to Poisson's ratios, friction angles, and cohesion values are referred to the proposals by Bowles [25] and Hunt [26], but when clear standards are presented in the guidelines, those values are used. For example, in Table 2, the compressional wave velocity of WR is $1,128 \mathrm{~m} / \mathrm{s}$, and WR is to be graded as a $\mathrm{V}$ grade of RMR 20 or less according to the RMR classification method from the case of rock classification in the road design guidelines of Korea Expressway Corporation (KEC) [27]. Therefore, the cohesion value of WR is set to 0.1 MPa. 


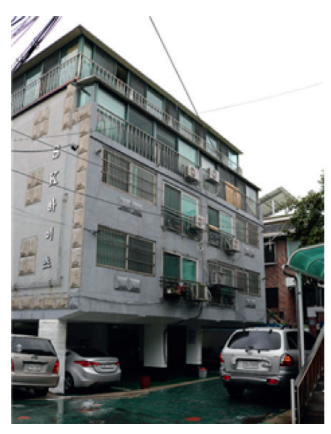

(a)

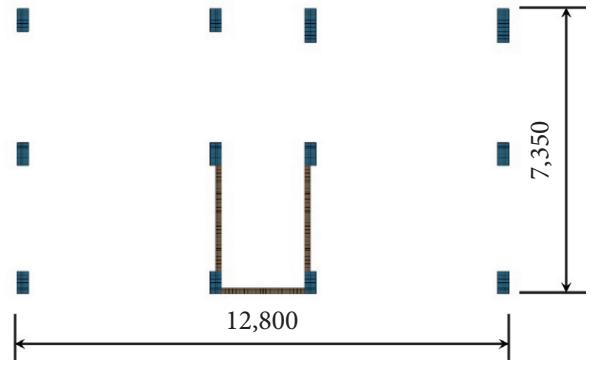

(b)

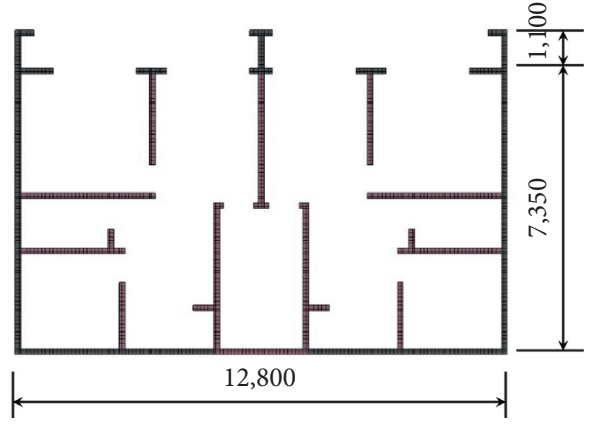

(c)

Figure 2: The objective structure of five-story piloti-type building for analysis. (a) Building appearance. (b) $1^{\text {st }}$ floor columns location and modeling. (c) $2^{\text {nd }}$ to $4^{\text {th }}$ floors wall location and modeling.

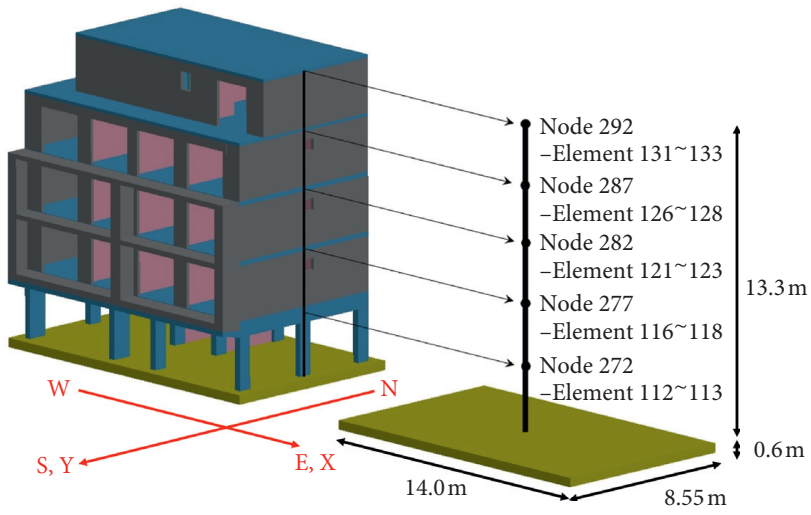

(a)

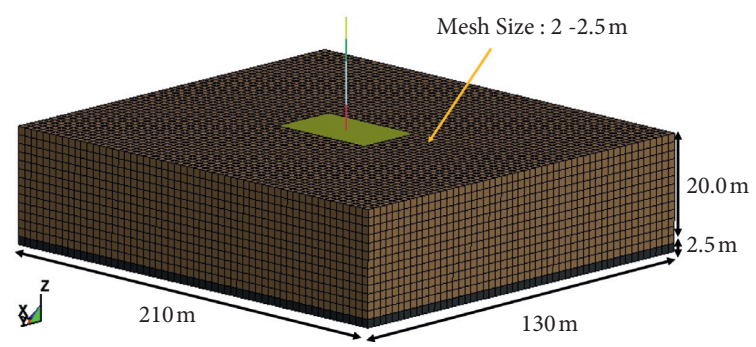

(b)

Figure 3: FE analysis models for the objective structure. (a) Building models (full and lumped mass). (b) Lumped mass structure + soil model for the SSI analysis.

TABLE 1: Geometric properties of the lumped mass frame FE model for the SSI analysis.

\begin{tabular}{|c|c|c|c|c|c|c|}
\hline Node \# & Element \# & Height (m) & Area $\left(\mathrm{m}^{2}\right)$ & $I_{x}\left(\mathrm{~m}^{4}\right)$ & $I_{y}\left(\mathrm{~m}^{4}\right)$ & Mass (tone) \\
\hline \multirow[t]{4}{*}{292} & 134,135 & 13.30 & 69.803 & Rigid & Rigid & 44.9569 \\
\hline & 133 & 13.17 & 8.828 & 0.02731 & 0.02287 & - \\
\hline & 132 & 12.77 & 6.990 & 0.07196 & 0.05553 & - \\
\hline & 131 & 11.97 & 7.395 & 0.18298 & 0.11402 & - \\
\hline \multirow[t]{4}{*}{287} & 129,130 & 10.77 & 98.150 & Rigid & Rigid & 81.8951 \\
\hline & 128 & 10.63 & 9.960 & 0.17667 & 0.21320 & - \\
\hline & 127 & 10.23 & 8.775 & 0.06016 & 0.09645 & - \\
\hline & 126 & 9.43 & 9.960 & 0.17667 & 0.21320 & - \\
\hline \multirow[t]{4}{*}{282} & 124,125 & 8.23 & 111.150 & Rigid & Rigid & 111.7912 \\
\hline & 123 & 8.03 & 10.583 & 0.90198 & 1.16289 & - \\
\hline & 122 & 7.63 & 9.473 & 0.32216 & 0.53120 & - \\
\hline & 121 & 6.83 & 10.583 & 0.90198 & 1.16289 & - \\
\hline \multirow[t]{4}{*}{277} & 119,120 & 5.63 & 111.150 & Rigid & Rigid & 113.3673 \\
\hline & 118 & 5.43 & 10.583 & 0.90198 & 1.16289 & - \\
\hline & 117 & 5.03 & 9.473 & 0.32216 & 0.53120 & - \\
\hline & 116 & 4.23 & 10.583 & 0.90198 & 1.16289 & - \\
\hline \multirow[t]{3}{*}{272} & 114,115 & 3.03 & 111.150 & Rigid & Rigid & 172.7695 \\
\hline & 113 & 2.33 & 3.510 & 0.06902 & 0.22394 & - \\
\hline & 112 & 1.17 & 3.510 & 0.06902 & 0.22394 & - \\
\hline
\end{tabular}

2.4. Properties of the Input Ground Motion and the Seismic SSI Analysis Procedure. The input excitation data used in this study are generated from the Gyeongju earthquake that occurred at the epicenter of $15 \mathrm{~km}$ deep in a region $8.7 \mathrm{~km}$ southwest of the city of Gyeongju on September 12, 2016 [28]. The magnitude of the earthquake is 5.8 and it is the 
TABLE 2: Geotechnical properties of four types of soil applied to the SSI analysis.

\begin{tabular}{|c|c|c|c|c|}
\hline Soil type & FI & AS & WS & WR \\
\hline Density $\left(\rho_{\text {soil }}\right)\left(\mathrm{kg} / \mathrm{m}^{3}\right)$ & 1,700 & 1,835 & 1,901 & 1,989 \\
\hline Unit weight $\left(\gamma_{\text {soil }}\right)\left(\mathrm{N} / \mathrm{m}^{3}\right)$ & 16,670 & 18,000 & 18,640 & 19,510 \\
\hline Shear modulus $(G)(\mathrm{MPa})$ & 58.813 & 136.151 & 211.835 & 720.461 \\
\hline Young's modulus $\left(E_{\text {soil }}\right)(\mathrm{MPa})$ & 158.796 & 353.993 & 550.772 & $1,801.154$ \\
\hline Bulk modulus $(K)(\mathrm{MPa})$ & 176.440 & 294.994 & 458.976 & $1,200.769$ \\
\hline Poisson's ratio $(v)$ & 0.35 & 0.30 & 0.30 & 0.25 \\
\hline Shear wave velocity $\left(V_{S}\right)(\mathrm{m} / \mathrm{s})$ & 186 & 283 & 353 & 651 \\
\hline Compressional wave velocity $\left(V_{P}\right)(\mathrm{m} / \mathrm{s})$ & 387 & 529 & 660 & 1,128 \\
\hline Friction angle $(\phi)\left({ }^{\circ}\right)$ & 30 & 30 & 31 & 33 \\
\hline Cohesion value $(C)(\mathrm{MPa})$ & 0 & 0.01 & 0.02 & 0.10 \\
\hline
\end{tabular}

largest one ever observed in Korea since seismic measurements began in 1978. The Gyeongju earthquake is of great significance in that the earthquake measurement history is short and the seismic wave of a certain magnitude or larger has been measured at relatively many stations in the Korean Peninsula, where the probability of occurrence of medium or large magnitude earthquakes is low [29]. For the seismic records considered in this study, data from three observatories (DAG2, YOCB, and MIYA) are selected in the order of the nearest distance from the epicenter, and the information related to the observatories is shown in Table 3 [28].

Figure 4 shows the acceleration response spectra of the observed seismic waves at the three stations and the acceleration time history data from the one that recorded the largest magnitude 5.8 at DAG2. The maximum earthquake acceleration is about $4.6 \mathrm{~m} / \mathrm{s}^{2}$ in EW direction and $5.3 \mathrm{~m} / \mathrm{s}^{2}$ in NS direction.

Figures 4(a) and 4(b) show the acceleration response spectra (RS) from each observatory and the design response spectra, which are normalized based on the initial ground acceleration (IGA) at $T=0.02 \mathrm{sec}$, and they are generated from the acceleration spectra (SA) with 2,400-year of reproduction cycle according to the seismic design standards for buildings [8].

The acceleration ground motion of the Gyeongju earthquake analyzed from a number of acceleration response spectrum data shows a dominant periodic range in the short periodic area of less than 0.3 seconds, and it creates a boundary of a constant acceleration period between about 0.1 and 0.3 seconds [29]. The effective maximum ground acceleration also shows a similar scale to the design spectrum, and from these results, the ground motion of the Gyeongju earthquake can be evaluated as like the DRS obtained in accordance with the building codes [30]. The procedure for carrying out the free-field and the seismic SSI analyses using the earthquake data in Figures 4(c) and 4(d) is as follows:

(1) Step 1: constructing ground FE models for each soil layer using the properties in Table 2 excluding the foundation and the lumped mass frame in Figure 3(b).

(2) Step 2: in the FE model of Step 1, the seismic load in Figure 4 is applied to the entire ground (the lowest part of the model), and the free-field response at the center of the ground surface is obtained. (The seismic
TABLE 3: Information on the three earthquake monitoring stations.

\begin{tabular}{lccccc}
\hline No. & Station & Location & $\begin{array}{c}\text { Latitude } \\
\left({ }^{\circ}\right)\end{array}$ & $\begin{array}{c}\text { Longitude } \\
\left({ }^{\circ}\right)\end{array}$ & $\begin{array}{c}\text { Distance } \\
(\mathrm{km})\end{array}$ \\
\hline 1 & DAG2 & Gyeongsan & 35.769 & 128.897 & 26.45 \\
2 & YOCB & Youngcheon & 35.977 & 128.951 & 32.34 \\
3 & MIYA & Milyang & 35.492 & 128.744 & 50.13 \\
\hline
\end{tabular}

wave in Figure 4 is assumed to be the response from the outcrop of a bedrock.)

(3) Step 3: the responses of the structure on the fixed base (NSSI: SSI effect is not considered) are calculated by applying the free-field response from Step 2 to the center of the foundation base of the lumped mass model without soil elements in Figure 3(a).

(4) Step 4: SSI interface elements are applied to the side and the lower interfaces of the foundation, and the free-field response obtained in Step 2 is applied to the center of the foundation in the FE model composed of the structure and the underlying soil together in Figure 3(b). The responses of the structures and the soil ground are calculated considering the SSI effects (SSI).

\section{Analysis Results and Parametric Study}

3.1. Results from the FE Model with the Gyeongju Earthquake. First, the analysis results from the Gyeongju earthquake applied to the soil-structure FE models described in Chapter 2 are summarized. Table 4 compares the fundamental transverse natural frequency results of the full model and the lumped mass model. As described in Section 2.2, as it is one of the conditions for constructing the equivalent lumped mass model, the values of the frequencies in EW direction are well coincided, but it can be found that there are relatively large differences in NS direction. This is an acceptable result since the staircase of the building is not located at the center of the floor plan, and the lumped mass model cannot take the effect of such eccentricity into account. Also, the results of the torsional modes are not considered because they have no further meaning to be compared due to the influence of this eccentricity effect.

Figure 5 shows the fundamental transverse mode shapes in each direction, and these results can be interpreted as the basic shapes of the horizontal displacement caused by 


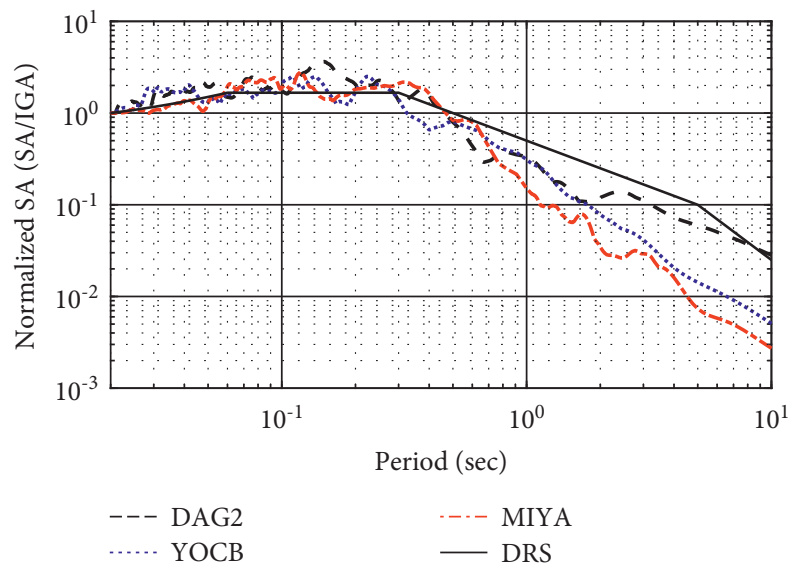

(a)

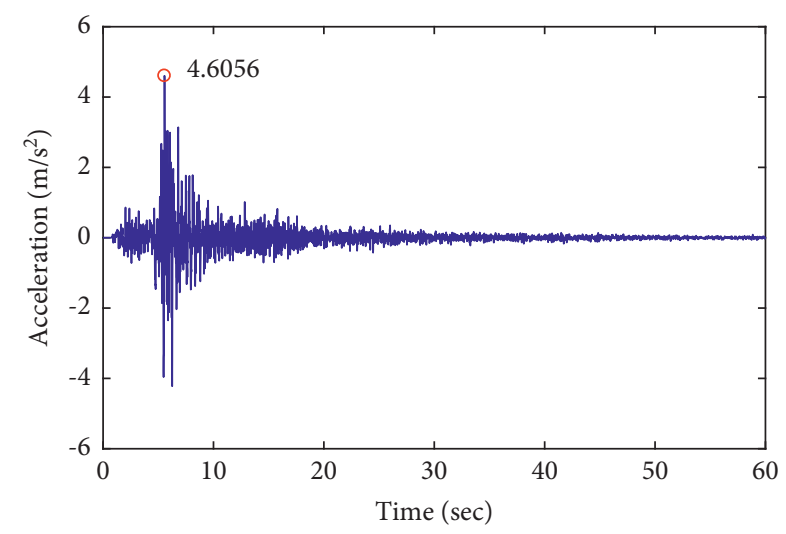

(c)

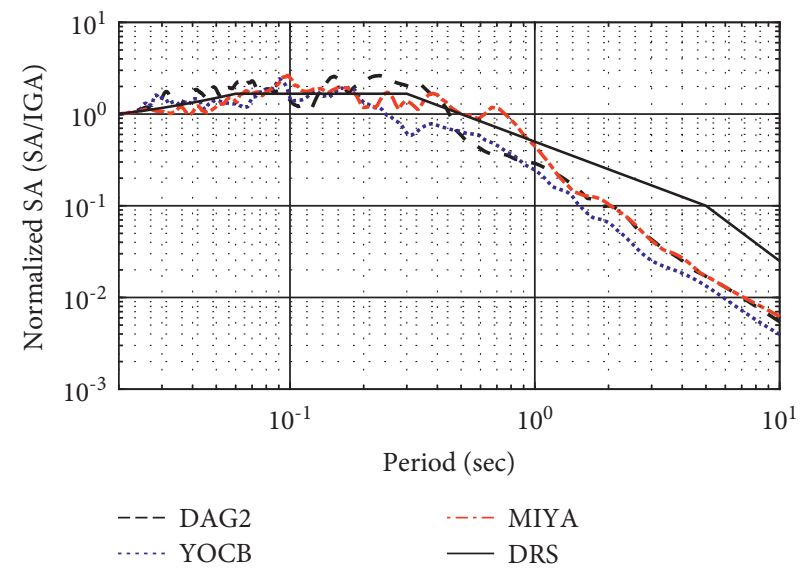

(b)

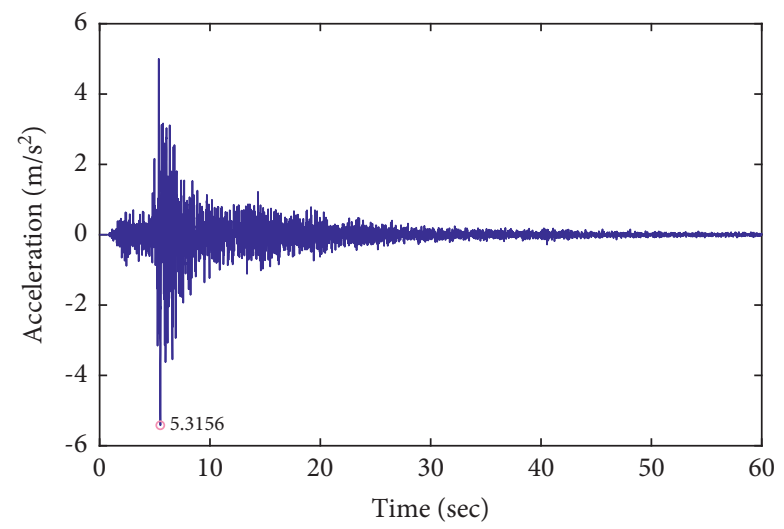

(d)

Figure 4: Acceleration response spectra and time history of Gyeongju earthquake monitored at three stations. (a) Comparison of normalized SA in EW direction. (b) Comparison of normalized SA in NS direction. (c) Acceleration time history in EW direction at DAG2. (d) Acceleration time history in NS direction at DAG2.

TABLE 4: Comparison of fundamental transverse natural frequencies between the full and lumped mass models (unit: Hz).

\begin{tabular}{lcccc}
\hline & \multicolumn{2}{c}{ EW direction } & \multicolumn{2}{c}{ NS direction } \\
Mode & Full & Lumped mass & 10.910 & Lumped mass \\
\hline $1^{\text {st }}$ & 8.232 & 8.231 & 29.055 & 12.404 \\
$2^{\text {nd }}$ & 24.237 & 24.235 & 25.417 \\
\hline
\end{tabular}

transverse dynamic loads. As can be found in the red dashed lines in the figures, the maximum relative displacement occurs on the first floor, when comparing the relative displacement at the top and the bottom of each floor. This is resulted from the difference in the stiffness between the first level (columns and walls) and the upper ones (shear walls), and it is the main reason of the failures in columns and walls shown in Figure 1. Therefore, the base shear generated at the foundation and the acceleration response at the top of the first floor are intensively analyzed in that the upper and lower ends of the first floor are the most vulnerable part of piloti-type structures under seismic events.

Figures 6 and 7 show the comparison results from the acceleration response spectra (ARS) on the bottom of the foundation from the free-field analysis for each soil condition by the Gyeongju earthquake and the ARS at the top of the first floor according to the presence (SSI) or absence (NSSI) of SSI effect for each ground and direction, respectively. It is natural that the peak of each spectrum should appear near the natural period $\left(T_{f}\right)$ of a soil system and the values are indicated next to the peaks in the ARS plots in Figure 6.

In Figure 7, it can be seen that the maximum value of the response of SSI decreases compared to that of NSSI. In Figures 7(a), 7(b), 7(e), and 7(f), the softer the soil system (FI, AS) is, the more the response peak occuring at the natural period $\left(T_{s}\right)$ of the structure is significantly reduced. Among the spectra peaks in Figure 7, the peak that appears in a relatively long period is due to $T_{f}$ and is consistent with the results of the free-field analysis. Also, the peaks appearing in the shorter period (EW: $0.12 \mathrm{sec}(8.3 \mathrm{~Hz}), \mathrm{NS}$ : $0.08 \mathrm{sec}(12.5 \mathrm{~Hz}))$ than $T_{f}$ are due to $T_{s}$ in each direction of 


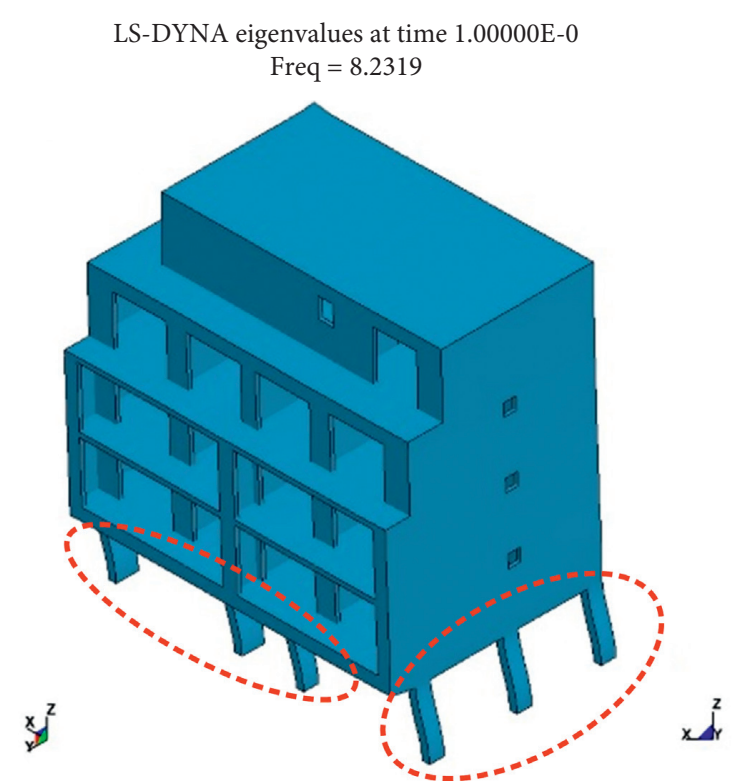

(a)

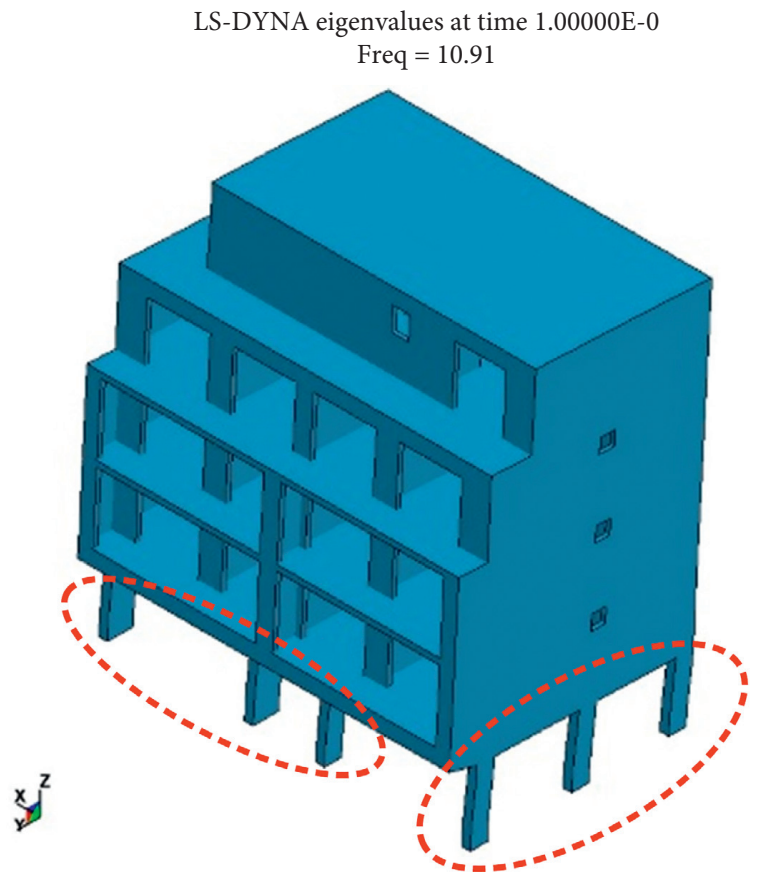

LS-DYNA eigenvalues at time 1.00000E-0

(b)
LS-DYNA eigenvalues at time 1.00000E-0 Freq $=8.2313$

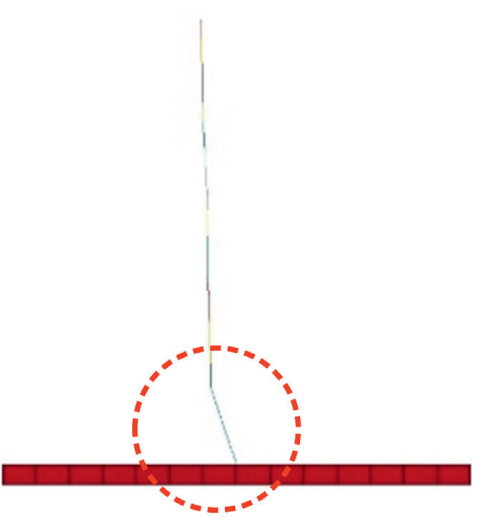

LS-DYNA eigenvalues at time 1.00000E-0 Freq $=12.404$

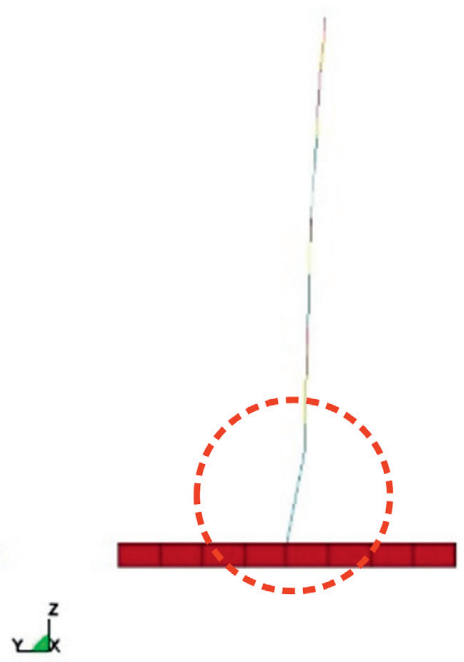

FIgURE 5: Fundamental transverse mode shapes of the full and lumped mass models in each direction. (a) EW direction (X-axis). (b) NS direction ( $Y$-axis).

the structural system and appear at the same period regardless of the soil type and the consideration of the SSI effect and are not seen in the free-field analysis results. In Figure 7(d), the acceleration responses of SSI and NSSI show incomparably larger values than those of the other ground conditions, and this result seems to be caused by the resonance phenomenon that the soil system of WR and the vibration characteristics of the structure in EW direction make $T_{f}$ and $T_{s}$ similar.

Here, if the period in which the SSI effect is largely affected is defined as a critical period (CP), the natural period of the structure $\left(T_{s}\right)$ in which the SSI effect significantly reduces the peak value of the response in Figure $7 \mathrm{can}$ be generally seen as the CP. This phenomenon is a result of the damping effect due to the absorption of the frequency component near the natural frequency of the structure because of the kinematic interaction of the underlying soil. On the other hand, in the vicinity of $T_{f}$ in all soil conditions, it can also be found that the response of the structure is amplified due to the SSI effect. Particularly for WS soil in EW direction (WS-EW) in Figure 7(c), it can be seen that the reduction of the response in $T_{s}$ appears similar to the 


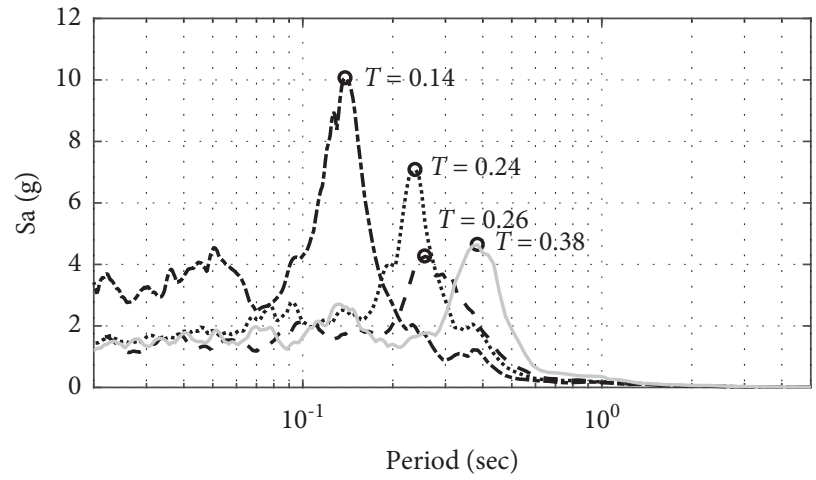

$\begin{array}{ll}- \text { FI } & \cdots . . \text { WS } \\ -- \text { AS } & \cdots-.- \text { WR }\end{array}$

(a)

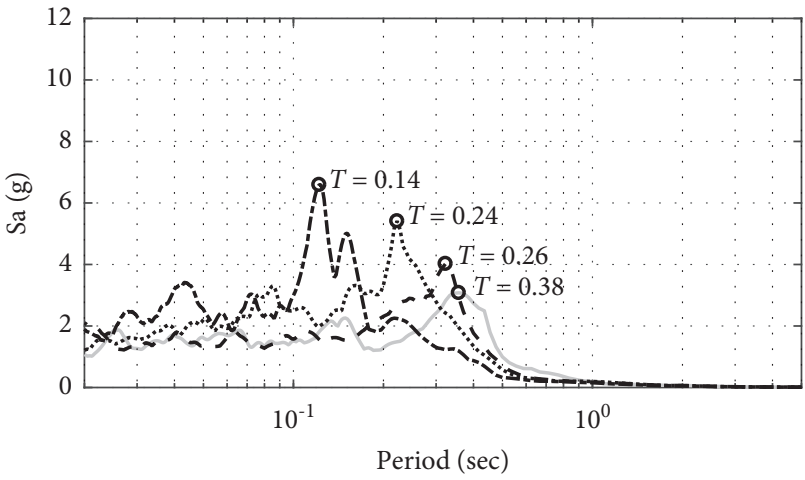

- FI $\quad \cdots \cdots$ WS

(b)

FIGURE 6: ARS and the periods where peaks appear for each soil condition in the free-field analysis by the Gyeongju earthquake. (a) EW direction. (b) NS direction.

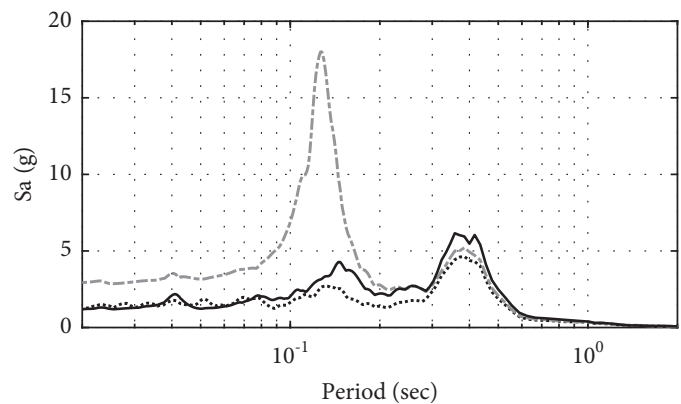

…. Free field

-..- NSSI

- SSI

(a)

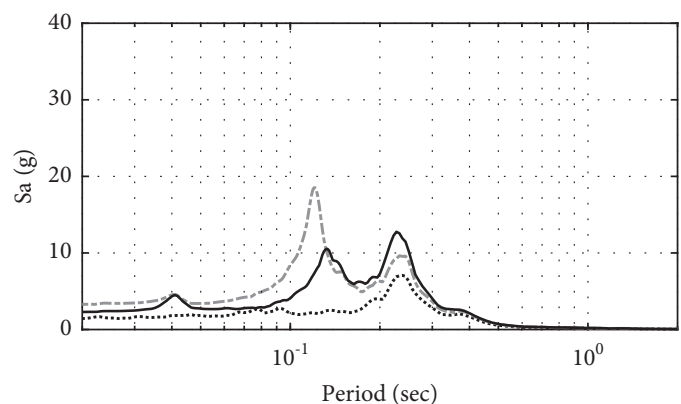

Free field

NSSI

- SSI

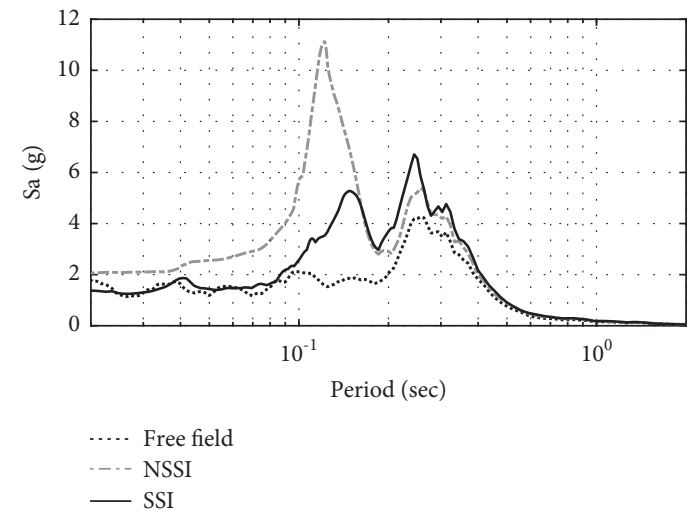

(b)

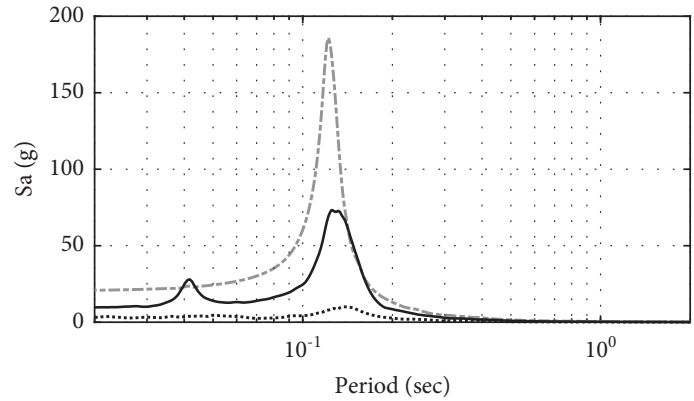

Free field

NSSI

(c)

(d)

Figure 7: Continued. 


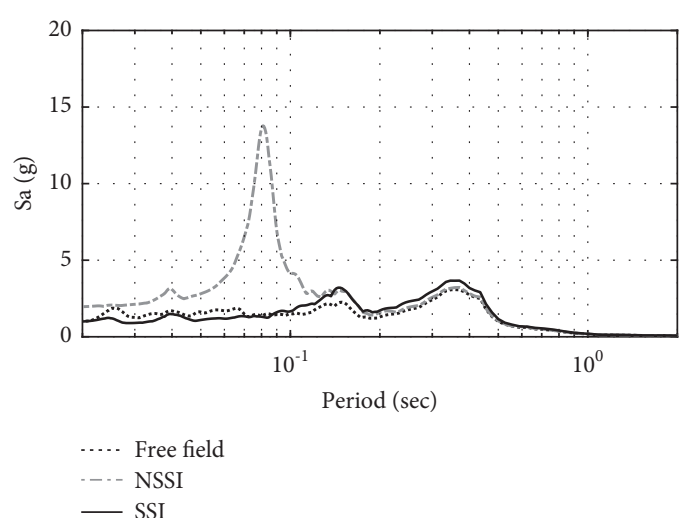

(e)

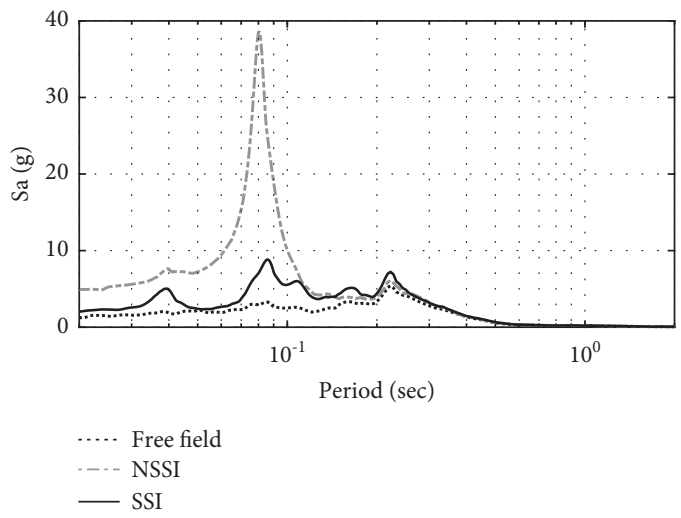

(g)

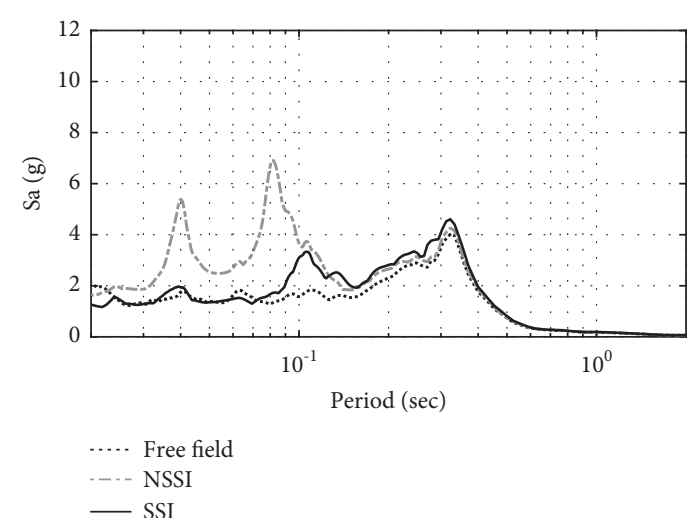

(f)

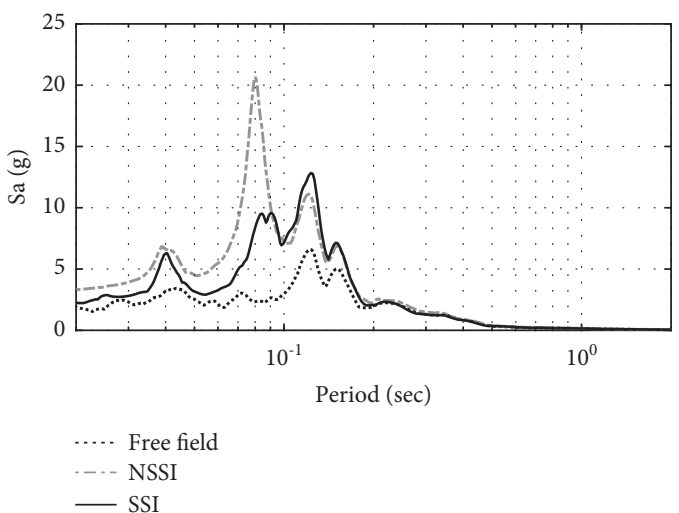

(h)

FIGURE 7: Comparison of ARS at the top of the $1^{\text {st }}$ floor for different soil conditions in each direction. (a) FI-EW. (b) AS-EW. (c) WS-EW. (d) WR-EW. (e) FI-NS. (f) AS-NS. (g) WS-NS. (h) WR-NS.

response amplification in $T_{f}$ in magnitude, so that the SSI effect does not sufficiently decrease the response. Thus, in certain soil and structural conditions, the increase in the response at $T_{f}$ occurs more than the decrease in the response at $T_{s}$, and then the phenomenon that the CP becomes $T_{f}$ instead of $T_{s}$ can also be expected.

Figure 8 shows the results of the root mean square (RMS) ratio (SSI/NSSI) of (a) the acceleration time history at the top of the first floor and (b) the time history data of the base shear at the surface of the foundation. As shown in the previous results, both acceleration and base shear responses due to the SSI effect are reduced in all soil conditions. In Figure 8 , the RMS ratio of the acceleration is $47 \%-76 \%$ in EW direction and $24 \%-77 \%$ in NS direction, and the RMS ratio of the base shear is $44 \%-72 \%$ in EW direction and $23 \%-67 \%$ in NS direction. However, in AS-NS and WS-EW, the response reduction effect by SSI is not large compared to the other soil conditions. This also seems to be caused by the phenomenon as described for WS-EW ARS results in Figure 7(c) where the reduction in response at $T_{s}$ and the response amplification at $T_{f}$ are similar. As such, the SSI effect caused by the Gyeongju earthquake shows very different patterns due to the change of the natural period $\left(T_{s}\right.$ and $T_{f}$ ) in accordance with the geotechnical properties of the underlying soil and the geometric properties of the upper structure even under the same seismic loading condition.
Therefore, a dimensional parameter is selected to evaluate the effect of the change of the fundamental transverse natural period $\left(T_{s}\right)$ in each direction that directly affects the response of the structure. In addition, the effect of the parameter on the base shear is analyzed through SSI analysis for each soil condition by using DRS according to the architectural design codes [8] as follows.

\subsection{Results from the Parametric Study with DRS Based on the Guideline [30]}

3.2.1. Dimensional Parameter. As described previously, the most important parameter in the structural dynamics in low-rise piloti system is the stiffness of walls and columns on the level of ground floor. Structural design guidelines for piloti buildings [31] give restriction on the ratio of the summation area of walls and columns in each direction on the pilotis (first) floor to the total floor area of the building in the seismic design of a piloti-type building with five or less stories. According to this guideline, in the case of building structures having the same number of floors, the summation area of columns and walls on the first floor is proportional to the total floor area, and it can also be assumed that the width in each direction of the structures is proportional to it. Therefore, in this study, the width in each direction of a 


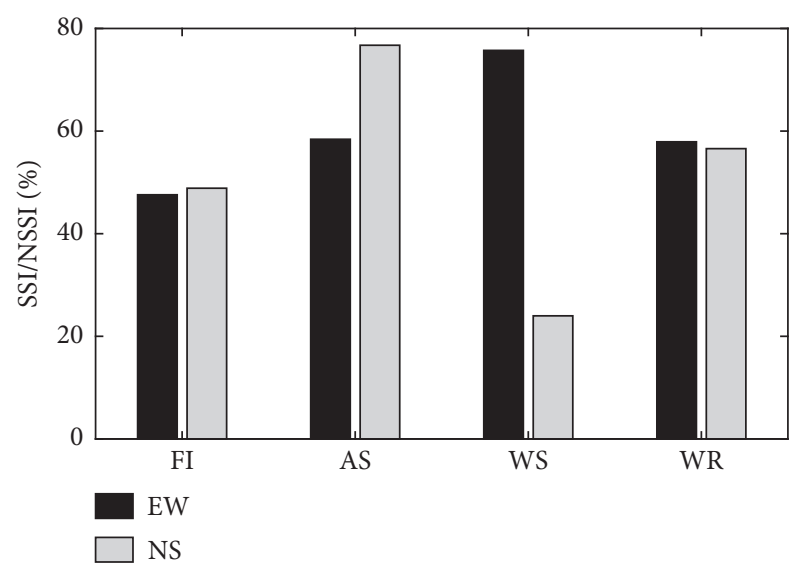

(a)

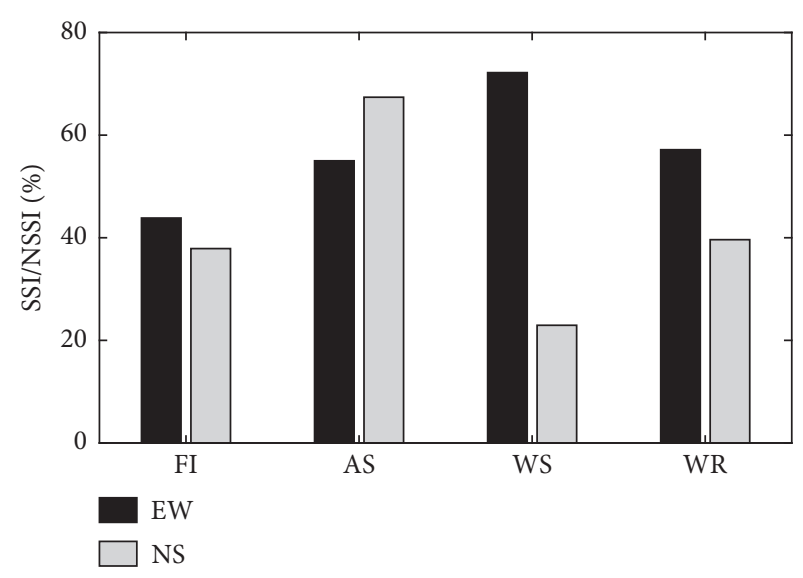

(b)

FIGURE 8: Results of RMS ratios (SSI/NSSI) of acceleration and base shear time history data with different soil conditions. (a) RMS ratio of the acceleration time history at the top of the $1^{\text {st }}$ floor. (b) RMS ratio of the base shear time history.

structure is selected as the main dimensional parameter for low-rise piloti-type structures, and the correlation between the changes in width and base shear is analyzed after conducting SSI analysis for each type of soil.

In order to derive realistic parameter values for the width of the structure, linear regression analysis is done with reference to the data [32] surveying the width of 48 residential piloti-type buildings as shown in Figure 9. As a result of the analysis, a linear equation: $W_{y}=0.633 W_{x}$ is obtained for $W_{x}$ (width in one direction) and $W_{y}$ (width in the other direction), and the dimension $\left(W_{x} \times W_{y}=14.0 \mathrm{~m} \times 8.5 \mathrm{~m}\right)$ of the original objective structure is in good agreement with the analyzed equation. Based on this result, the models with increasing and decreasing $W_{x} \times W_{y}$ are selected as $18.0 \mathrm{~m} \times$ $11.29 \mathrm{~m}$ and $10.0 \mathrm{~m} \times 6.3 \mathrm{~m}$, respectively. Table 5 summarizes the width and the ratio of height/width for each model and the fundamental transverse natural period in each direction.

In Table 5, ORG means the original model and WUP and WDN, the ones with increased and decreased widths. When constructing the analysis models, not only the area of the first-floor columns and walls is changed according to the variation in the width, but the stiffness is also changed in consideration of the change in the diameter of rebars so that the reinforcement ratio keeps.

3.2.2. Design Response Spectra (DRS). In this study, according to the seismic design criteria for buildings [30], the theoretical DRS is constructed under the conditions of a 2,400-year reproduction cycle, S1 bedrock ground and seismic zone \#1, then the trapezoidal envelope method is applied to generate artificial seismic time history data for $0 \mathrm{sec}-17 \mathrm{sec}$, and finally a total of six time history data are generated in each direction of EW and NS. The maximum seismic ground acceleration (SGA) of the generated time history data in this way is $1.77 \mathrm{~m} / \mathrm{s}^{2}-2.26 \mathrm{~m} / \mathrm{s}^{2}$. Figures 10 (a) and $10(\mathrm{~b})$ show the theoretical DRS based on the design guideline and an example of the six artificial seismic time history data, respectively. By using these artificial data as

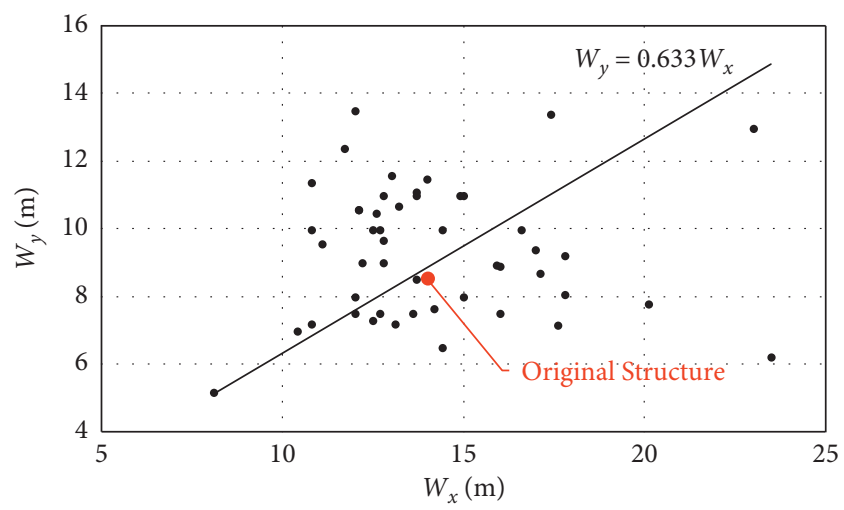

FIgURE 9: Regression result from the width data of 48 piloti buildings [32].

TABle 5: Structural dimensional parameters and fundamental natural periods for parametric study models.

\begin{tabular}{lcccccc}
\hline \multirow{2}{*}{ Model type } & \multicolumn{2}{c}{ Width $(\mathrm{m})$} & \multicolumn{2}{c}{ Ratio $(H / W)$} & \multicolumn{2}{c}{$1^{\text {st }}$ natural } \\
& $W_{x}(\mathrm{~m})$ & $W_{y}(\mathrm{~m})$ & $H / W_{x}$ & $H / W_{y}$ & $\mathrm{EW}(x)$ & $\mathrm{NS}(y)$ \\
\hline ORG & 14.0 & 8.55 & 0.17 & 0.27 & 0.1215 & 0.0806 \\
WUP & 18.0 & 11.29 & 0.13 & 0.21 & 0.1172 & 0.0819 \\
WDN & 10.0 & 6.33 & 0.23 & 0.37 & 0.1289 & 0.0821 \\
\hline
\end{tabular}

input values, free-field, NSSI, and SSI analysis are performed according to the procedure described in Chapter 2, and the results are averaged.

3.2.3. Results of the Parametric Study. In order to analyze the effect of the SSI on the base shear according to the change in the width $\left(W_{x}=18.0 \mathrm{~m}, 14.0 \mathrm{~m}, 10.0 \mathrm{~m} \quad\right.$ and $\left.W_{y}=11.4 \mathrm{~m}, 8.5 \mathrm{~m}, 6.3 \mathrm{~m}\right)$ of the structure, the change of the ratio (SSI/NSSI) is shown in Figure 11. It means that the smaller the value of the ratio, the greater the reduction of base shear by SSI effect and that the base shear by SSI effect 


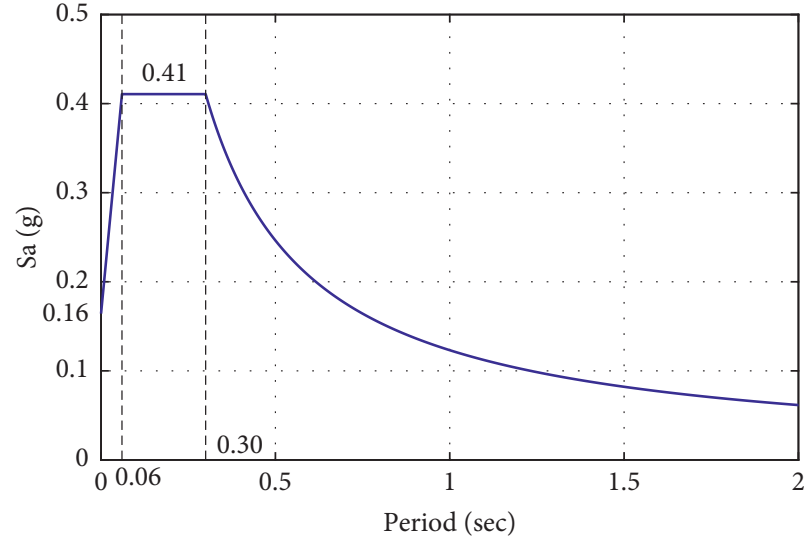

(a)

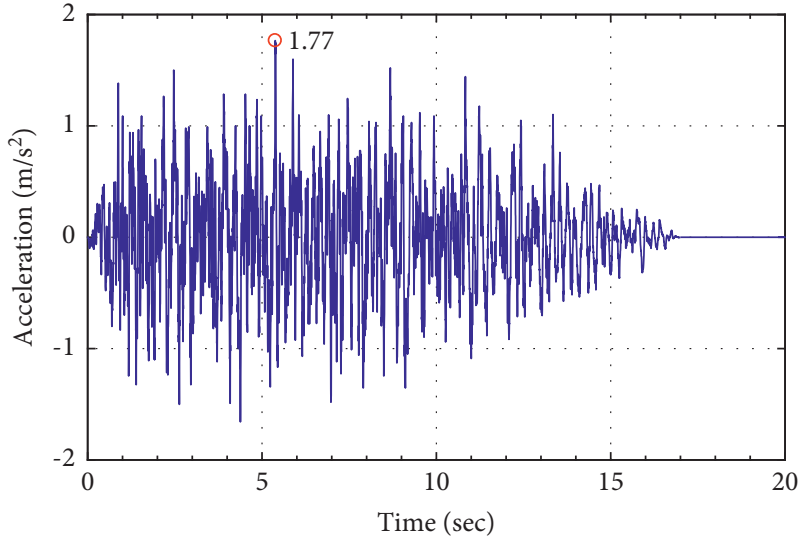

(b)

FIgURe 10: Design response spectrum (DRS) and a time history data of artificial earthquakes used for the parametric study. (a) Design response spectrum (DRS). (b) A time history data from the DRS.

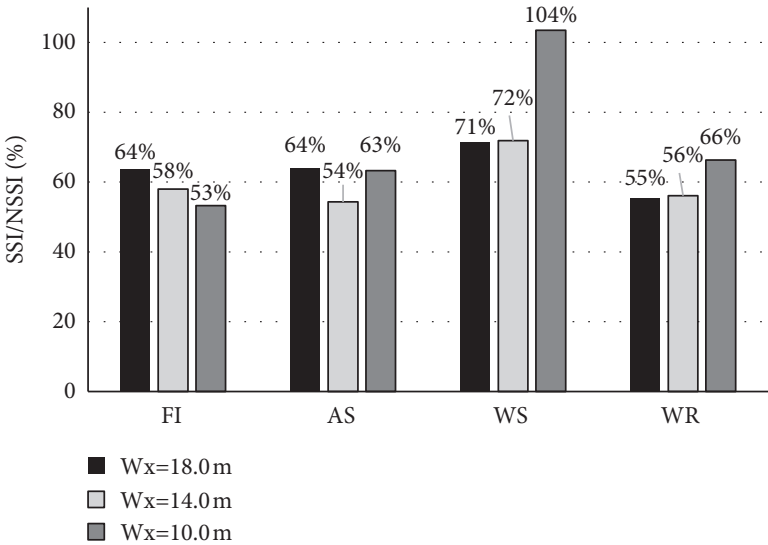

(a)

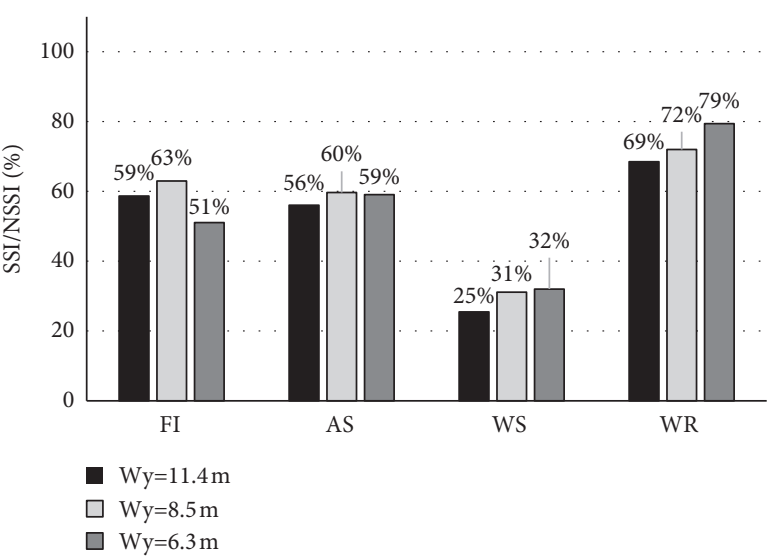

(b)

FIgURE 11: Ratio (SSI/NSSI) of base shear values according to the width change with different soil conditions in each direction. (a) EW direction. (b) NS direction.

augments compared to the case of NSSI if the ratio exceeds $100 \%$.

As shown in the results, the ratios (SSI/NSSI) are $51 \%-$ $64 \%$ in FI, $54 \%-64 \%$, in AS, $25 \%-104 \%$ in WS, and $55 \%-$ $79 \%$ in WR. The SSI effect reduced the response of the base shear in all soil conditions except for one case showing more than $100 \%$ in WS-EW. In both FI and AS soil conditions, there is no clear trend in the change of the ratio as the width of the structure increases or decreases in both directions, but in WS and WR, the reduction in response due to the SSI effect tends to decrease as the width decreases (WS:71\% $\longrightarrow$ 104\%, WR: $55 \% \longrightarrow 66 \%$ in EW direction, WS: $25 \% \longrightarrow 33 \%$, WR: $69 \% \longrightarrow 79 \%$ in NS direction). This phenomenon infers that the reduction in stiffness due to the decrease of the width results in the increase of the natural period as summarized in Table 5, and as a result, the newly modified natural period becomes similar to that of the hard soils (Table 6) as well as the response gets relatively large when the SSI effect is considered. In case of WS-EW, it can be seen that the response ratio becomes $104 \%$ when $W_{x}=10.0 \mathrm{~m}$, which
TABLE 6: The periods $\left(T_{f}\right)$ where the peak appears in free-field response spectrum for each soil type in different direction (unit: sec).

\begin{tabular}{lcc}
\hline Soil type & EW & NS \\
\hline FI & 0.39 & 0.40 \\
AS & 0.28 & 0.28 \\
WS & 0.21 & 0.22 \\
WR & 0.13 & 0.12 \\
\hline
\end{tabular}

shows that the SSI effect rather increases the response of the base shear.

As for general structural dynamics problems, most engineering attention is given to the case where the dynamic characteristics of the underlying soil and structural systems match; that is, the natural frequencies of the two systems coincide and resonance occurs $\left(T_{f} \cong T_{s}\right)$. However, as shown in the results from the Gyeongju earthquake in Figure $7(\mathrm{~d})$, it is confirmed that the SSI effect still reduces the acceleration response even for WR-EW $\left(T_{f} \cong T_{s}\right.$ and the 


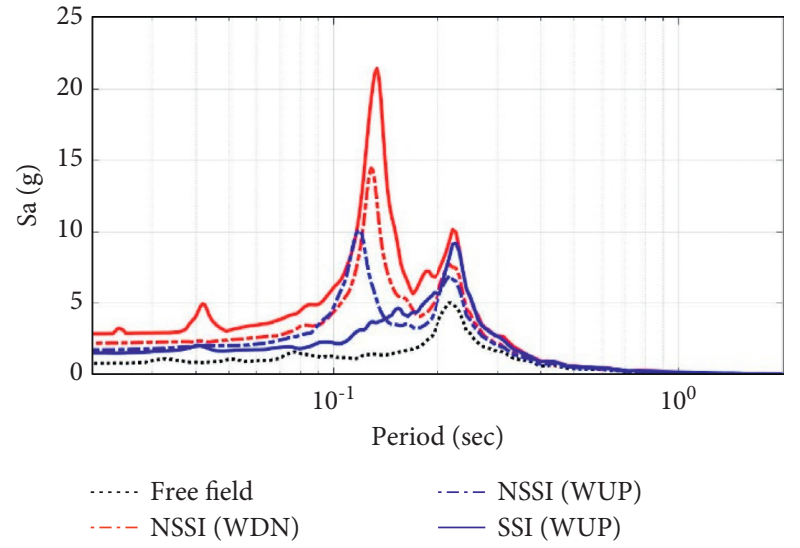

(a)

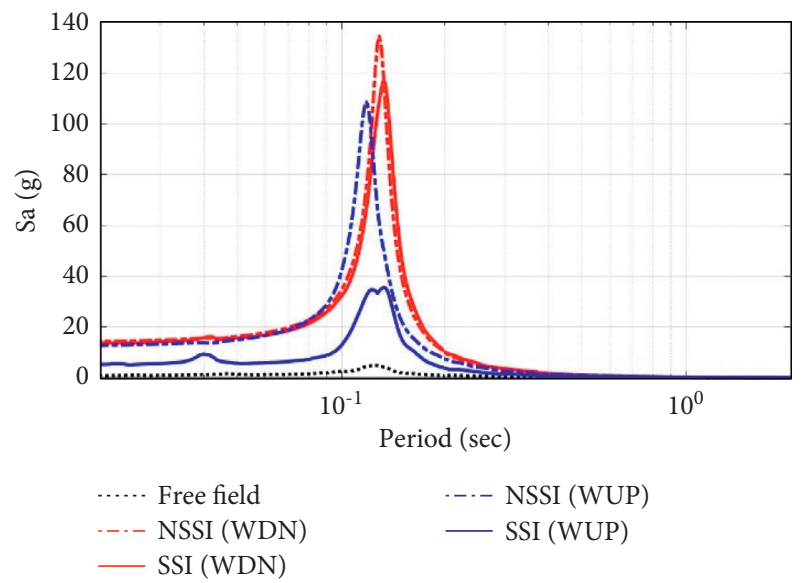

(c)

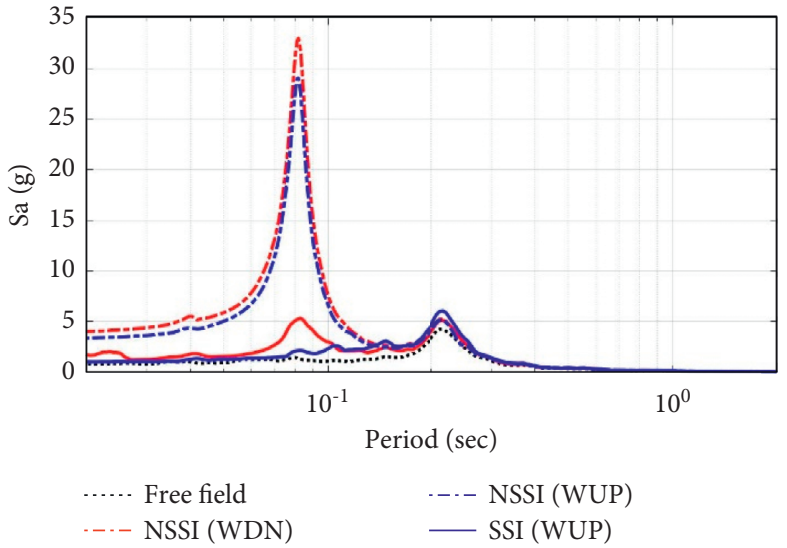

(b)

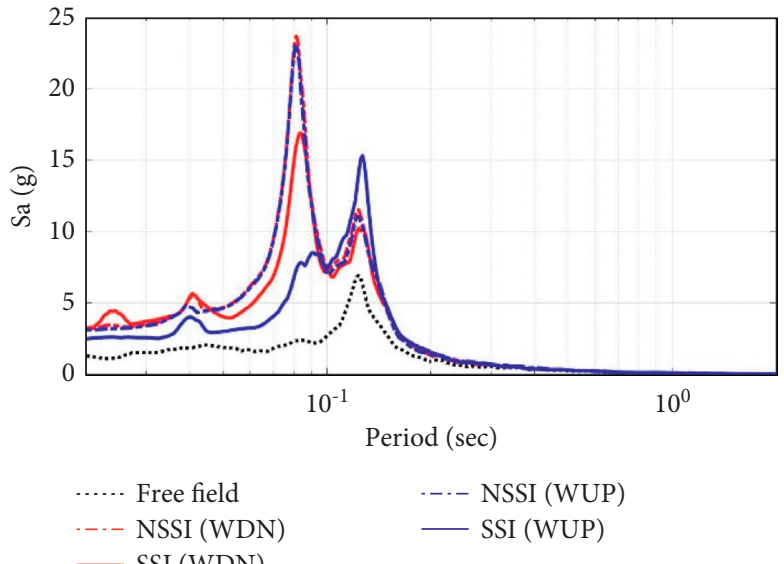

(d)

FIGURE 12: ARS at the top of the $1^{\text {st }}$ floor according to the width change for WS and WR in each direction. (a) WS-EW, (b) WS-NS, (c) WREW, (d) WR-NS.

scale of the response is very large compared to the other cases) as shown in Figure 12(c). On the other hand, in this study, the results from WS soil condition, which are not related to the resonance problem, show the most irregular results regardless of the dimension or the direction of the structural system.

As shown in Figure 11, the SSI effect of WS soil does not significantly reduce the base shear in EW direction or exhibits it in the amplifying direction; however, it causes the largest reduction in NS direction on the contrary. This difference is evident in the results of Figure 12(a), and the same phenomenon is found in Figures $7(\mathrm{c})$ and $7(\mathrm{~g})$ from the Gyeongju earthquake with the same soil condition. Meanwhile, one thing to be noted in the result is that the reason for the amplification of the acceleration response in WDN $\left(W_{x}=10.0 \mathrm{~m}\right)$ with WS-EW in Figure 12(a) is not because of the reversal of the critical period (CP) from $T_{s}$ to $T_{f}$ unlike the results in Figure 7(c). In this case, it is observed that the response amplification occurs at both periods of $T_{f}$ and $T_{s}$, and the magnitude at $T_{s}$ is much greater than that of $T_{f}$. Thus, it is found that the SSI effect according to the type of underlying soil cannot be completely quantified by analyzing only the dynamic characteristics of the soil and structural systems. In particular, it is judged that the phenomenon that the SSI effect amplifies the response is caused by a combination of various variables. Therefore, it seems necessary to confirm the effects of these variables through direct SSI analysis for specific soil and structural conditions.

Finally, in Figure 13, the relationship between the $H / W$ ratio and the SSI effect on the base shear is analyzed through forming the distribution graphs of the SSI/NSSI ratio for the base shear ( $y$-axis) to the $H / W$ ratio ( $x$-axis) as shown in Table 5.

The SSI effect of FI and AS consistently reduces the response to an average of $58 \%$ regardless of the $H / W$ ratio in Figure 13. For WR soil, as the $H / W$ ratio increases, the SSI/ NSSI ratio increases from $55 \%$ to $79 \%$. From a linear regression analysis, $y=1.5087 x+0.4193$ is obtained as a result. Therefore, considering the SSI effect in a 5-story piloti-type building with a height of $2.3 \mathrm{~m}$ and a width of $6.3 \mathrm{~m}$ to $18.0 \mathrm{~m}$, the base shear value from the fixed base analysis in FI and AS soil conditions is reduced to about an average of $58 \%$, and in WR soil condition, it is evaluated to be linearly varied from $55 \%$ to $79 \%$ as the change of the $H / W$ 


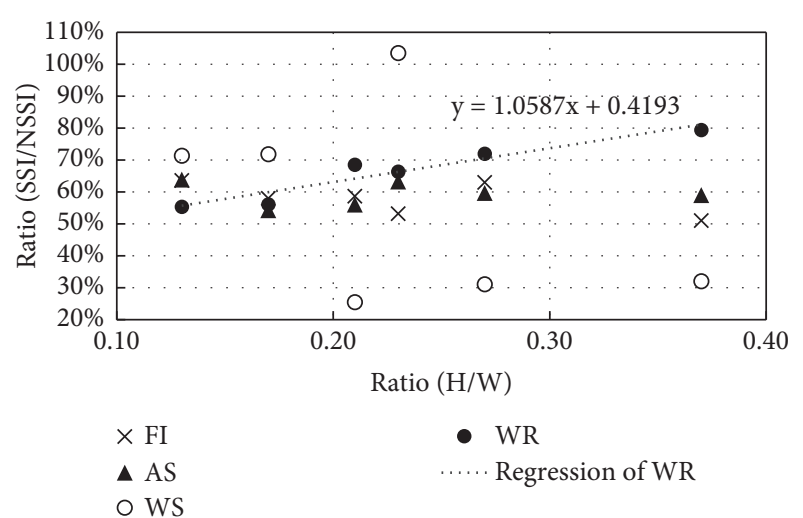

FIGURE 13: Distribution of correlation between $H / W$ ratio and SSI/ NSSI ratio.

ratio. These values show somewhat smaller prediction results than the $80 \%$ reduction limit of base shear when considering the SSI effect suggested by the guideline presented in the seismic design standards for buildings [8], and it can be found that the current standard sets a conservative reduction rate for the influence of the SSI effect. From this result, a simple and reasonable prediction basis for the influence of SSI effect in 5-story piloti-type buildings constructed on FI, AS, and WR soil ground is provided by this study. However, since WS soil type shows high irregularity in results depending on the structural conditions and the analysis direction as described previously, it would be reasonable to conduct a separate SSI analysis to determine the effect more precisely.

\section{Conclusion}

The results obtained by analyzing the five-story piloti-type building structure using the Gyeongju earthquake are as follows:

(1) No clear correlation between the soil type and the change in acceleration and base shear responses is seen depending on the seismic SSI, but when the influence of the SSI is considered, due to the kinematic interaction effect, the response of base shear significantly decreases to $44 \%-72 \%$ in EW direction and $23 \%-67 \%$ in NS direction depending on the type of underlying soil condition.

(2) In WR soil condition, a resonance occurs as the fundamental natural periods of the ground $\left(T_{f}\right)$ and the structure $\left(T_{s}\right)$ become similar, but the SSI effect still acts in the direction of reducing the response of the structure.

(3) Overall, the SSI effect acts in the direction of reducing the responses in acceleration and base shear by reducing the peak value of the response at the natural period $\left(T_{s}\right)$ of the structure, but rather amplifies the response of the structure in the vicinity of the natural period $\left(T_{f}\right)$ of the ground. Thus, the total SSI effect should be evaluated by summing the changes in the responses at $T_{s}$ and $T_{f}$.
The results derived from the parametric study conducted by changing the width $(6.3 \mathrm{~m}-18.0 \mathrm{~m})$ of the five-story pilotitype building with a height of $2.3 \mathrm{~m}$ on the first floor are summarized as follows:

(1) In FI and AS ground conditions, no clear trend is seen in the relationship between the variation in the width of the structure and the base shear response by the SSI, but in WS and WR, the reduction effect of the base shear response by the SSI tends to decrease as the width of the structure becomes small.

(2) The SSI effect is evaluated to reduce the base shear from the fixed base analysis by an average of $58 \%$ in FI and AS soil conditions, and to $55 \%-79 \%$ in WR ground.

(3) Comparing the above results with the seismic design standard [8] of the building, it can be estimated that the $80 \%$ of the reduction limit of the base shear for the consideration of the SSI effect suggested in the design standard sets a somewhat conservative rate.

(4) In EW direction of WS ground, contrary to general expectations, the SSI effect augments the response of the base shear compared with the result from the case where the fixed base is assumed. In addition, the response of each direction on WS shows relatively high irregularity in results compared to the other ground conditions. Therefore, when it is difficult to consistently predict the SSI effect under specific ground and structural conditions as seen in the WSEW condition, a direct analysis for the SSI seems to be necessary.

The suggested values and equations for the SSI effect presented in this study are analyzed based on the results from the analysis conducted with limited variables and parameters by the researchers to date. The research gap found through this study is as follows:

(1) This study can be rationally applied to structures of similar shape (floor and scale) with a similar ratio of the area between the columns and walls to the floor area. To generalize this study, more parametric studies and experimental proof are needed.

(2) Also, in this study, the ground was modeled as a single soil layer to analyze the effect of the physical properties of each soil layer on the SSI. However, the soil layer is not only composed of several layers of different soils, but also contains groundwater. Therefore, it is difficult to apply the results of this study to complex ground where it is necessary to consider the influence of multiple soil layers including the effect of groundwater.

\section{Data Availability}

The input earthquake analysis data used to support the findings of this study are available from the corresponding author upon request. 


\section{Conflicts of Interest}

The authors declare that they have no conflicts of interest.

\section{Acknowledgments}

This research was supported by the Basic Science Research Program through the National Research Foundation of Korea (NRF2018R1A6A1A0702581921).

\section{References}

[1] T. Kim, Y. Chu, Y. Chu, S. R. Kim, and D. Bhandari, "Seismic behavior of domestic piloti-type buildings damaged by 2017 Pohang earthquake," Journal of the Earthquake Engineering Society of Korea, vol. 22, no. 3, pp. 161-168, 2018.

[2] K. Danish and R. Aruna, "'Nonlinear seismic analysis of masonry infill RC buildings with eccentric bracings at soft storey level," in Proceedings of the World multidisciplinary civil engineering-architecture-urban planning symposium (WMCAUS 2016), vol. 161, pp. 9-17, Prague, Czech Republic, June 2016.

[3] RMS (Risk Management Solusions), Chi-Chi, Taiwan Earthquake (Event report), Risk Management Solutions, Inc., Taiwan, China, 2000.

[4] T. Eom, S. Lee, and H. Park, "Investigation of structural damage in bearing wall buildings with pilotis by 2017 Pohang earthquake," Journal of the Earthquake Engineering Society of Korea, vol. 23, no. 1, pp. 161-168, 2019.

[5] C. Yoo, T. Kim, T. Kim, and Y. Chu, "Seismic performance evaluation of small-size pilloti-type reinforced concrete buildings using nonlinear dynamic analysis," Journal of the Earthquake Engineering Society of Korea, vol. 20, no. 4, pp. 191-199, 2016.

[6] KGS (Korean Geotechnical Society), Commentary for Foundation Design Code, Korean Geotechnical Society, Korea, 2015.

[7] H.-U. Kim, J. Ha, J.-G. Ha, D.-S. Kim, and K.-H. Joo, "Overview on standards for soil-structure interaction analysis used in design of infrastructure - structure interaction analysis used in design of infrastructure," Journal of the Earthquake Engineering Society of Korea, vol. 21, no. 5, pp. 227-236, 2017.

[8] MLITK (Ministry of Land, Infrastructure and Transport of Korea), Seismic Design Standards for buildings, Ministry of Land, Infrastructure and Transport of Korea, Korea, 2019.

[9] E. S. Abdel, M. M. Ahmed, and T. M. Alazrak, "Soil-raft foundation structure interaction effects on seismic performance of multi-story MRF buildings," Engineering Structures and Technologies, vol. 6, no. 2, pp. 43-61, 2014.

[10] V. T. Bhojegowda and K. GSubramanya, "Soil structure interaction of framed structure supported on different types of foundation," International Research Journal of Engineering and Technology, vol. 2, no. 5, pp. 651-660, 2015.

[11] A. K. Jha, K. Utkarsh, and R. Kumar, "Effects of soil-structure interaction on multi storey buildings on mat foundation," Advances in Structural Engineering, pp. 703-715, 2015.

[12] ASCE (American Society of Civil Engineers), Minimum design loads and associated criteria for buildings and other structures, ASCE, Reston, VA, USA, 2016.

[13] H. Tahghighi and A. Mohammadi, "Numerical evaluation of soil-structure interaction effects on the seismic performance and vulnerability of reinforced concrete buildings,"
International Journal of Geomechanics, vol. 20, no. 6, Article ID 04020072, 2020.

[14] V. Anand and S. R. K. Satish, "Seismic soil-structure interaction: a state-of-the-art review," Structure, vol. 16, pp. 317326, 2018.

[15] J. Bielak, K. Loukakis, Y. Hisada, and C. Yoshimura, "Domain reduction method for three-dimensional earthquake modeling in localized regions, Part I: theory," Bulletin of the Seismological Society of America, vol. 93, no. 2, pp. 817-824, 2003.

[16] LSTC (Livermore Software Technology Corporation), LSDYNA Keyword User's Manual, Livermore Software Technology Corporation, Livermore, CA, USA, 2018.

[17] C. Bolisetti, A. S. Whittaker, and J. L. Coleman, "Linear and nonlinear soil-structure interaction analysis of buildings and safety-related nuclear structures," Soil Dynamics and Earthquake Engineering, vol. 107, pp. 218-233, 2018.

[18] B. R. Jayalekshmi and H. K. Chinmayi, "Effect of soil stiffness on seismic response of reinforced concrete buildings with shear walls," Innovative Infrastructure Solutions, vol. 1, no. 2, 2016.

[19] G. Lee, K. Hong, E. Lee, and J. Kim, "Verification of linear FE model for nonlinear SSI analysis by boundary reaction method," COSEIK Journal Computational Structural Engineering, vol. 27, no. 2, pp. 95-102, 2014.

[20] D. Yoon, H. Song, W. Jang, and C. Min, "Modifed modulus of elasticity of concrete column with steel bar," Journal of the Korea institute for structural maintenance and inspection, vol. 9, no. 1, pp. 101-111, 2005.

[21] I. Chowdhury and S. Dasgupta, Dynamics of Structure and Foundation - A Unified Approach I. Fundamentals, CRC Press, Balkema, Leiden, The Netherlands, 2009.

[22] C.-G. Sun, J.-T. Han, and W. Cho, "Representative shear wave velocity of geotechnical layers by synthesizing in-situ seismic test data in Korea," Journal of Engineering Geology, vol. 22, no. 3, pp. 293-307, 2012.

[23] C. G. Sun, D. S. Kim, and C. K. Chung, "Geologic site conditions and site coefficients for estimating earthquake ground motions in the inland areas of Korea," Engineering Geology, vol. 81, no. 4, pp. 446-469, 2005.

[24] Electric Power Research Institute (Epri), Screening, Prioritization and Implementation Details (SPID) for the Resolution of Fukushima Near-Term Task Force Recommendation 2.1, Seismic, Palo Alto, CA, USA, 2013.

[25] E. J. Bowles, Foundation Analysis and Design, McGraw-Hill, Maidenhead, England, 5th edition, 1996.

[26] E. R. Hunt, Geotechnical Engineering Investigation Handbook, CRC Press, Boca Raton, FL, USA, 2nd edition, 2005.

[27] KEC (Korea Expressway Corporation), Road Design Guidelines Ch.9-1 Tunnel, Korea Expressway Corporation, Korea, 2009.

[28] NECIS (National Earthquake Comprehensive Information System), 2019.

[29] D. Shin, S. Hong, and H. Kim, "Investigation on effective peak ground accelerations based on the Gyeongju earthquake records," Journal of the Earthquake Engineering Society of Korea, vol. 20, no. 7, pp. 425-434, 2016.

[30] AIK (Architectural Institute of Korea), Korea Building Code and Commentary, Architectural Institute of Korea, Korea, 2016.

[31] MLITK (Ministry of Land, Infrastructure and Transport of Korea), Structural Design Guidelines for piloti-buildings, Ministry of Land, Infrastructure and Transport of Korea, Korea, 2018.

[32] C. Cho, "Comparative evaluation on the seismic responses for a low-rise RC residential buliding model with and without retrofit," Master's thesis, Korea University, Seoul, Korea, 2011. 